\title{
Research on the Application of Consumer Psychology Theory in Real Estate Marketing
}

\author{
Runhan Hou ${ }^{1}$ \\ 107 Rockywood Road, Manhasset, NY, 11030, United States \\ 1026301148@qq.com \\ Runhan $\mathrm{Hou}$
}

Keywords: real estate, marketing strategy, consumer psychology

\begin{abstract}
With the development of economic society, the real estate industry plays a vital role in national economy and greatly correlates with other industries. This paper reviews the current mature marketing theory and related concepts of consumer psychology, and combines the characteristics of real estate marketing, focusing on the position and application of consumer psychology in real estate marketing from the perspective of customer psychology.
\end{abstract}

\section{Research background}

The real estate industry is one of the pillar industries of the national economy and plays a vital role in economic development and social stability. At the same time, the real estate industry and other industries have strong correlation. With statistics, there are more than 70 upstream and downstream industries related to the real estate industry. The driving coefficient for industry is $1: 3$, and the driving coefficient for employment is 1:2. It has an irreplaceable role in driving the development of related industries and stimulating employment ${ }^{[1]}$. Therefore, it is particularly important to study the real estate marketing theory in depth and to develop a successful real estate marketing strategy. For China, the history of real estate development is not long. The marketing theory of real estate is still relatively weak. It still needs a guide to real effective marketing strategies.

Among many factors, whether the real estate marketing strategy can truly meet the needs of consumers has always been the key to the formulation of marketing strategies. The success of modern marketing ideas is largely a correct grasp of consumer psychology, corporate marketing strategies. The formulation requires an in-depth study of the internal needs of consumers, so that relevant projects are recognized by consumers, thereby achieving project value.

In this regard, this paper reviews the current mature marketing theory and related concepts of consumer psychology, and combines the characteristics of real estate marketing, focusing on the position and application of consumer psychology in real estate marketing from the perspective of customer psychology.

\section{Current status of marketing theory research}

Marketing theory is an applied science in which enterprises regard marketing activities as research objects ${ }^{[2]}$. Since the development of the 1930 s, many theories have been published. According to the different characteristics of the times, the most famous are the 4P, 4C and 4R marketing theories.

The 4P theory ${ }^{[3]}$ was proposed by the famous American marketing scientist McCarthy in the $1960 \mathrm{~s}$. The theory divides the marketing process into four elements: Product, Price, Place, and Promotion. McCarthy believes that a successful marketing only requires companies to produce quality products, find the right dealers to develop reasonable prices, and use appropriate promotional methods. The 4P theory mainly studies marketing issues from the perspective of enterprises, and its fundamental goal is to meet current market demands. Although the 4P theory focuses on the product itself rather than the consumer, and does not consider the role of consumers in marketing, it simplifies and 
systematically complicates complex marketing activities and lays a solid foundation for the establishment of marketing.

Following the 4P theory, in the 1980s, American marketing scientist Robert Lauterborn proposed the 4C theory based on the consumer core, namely: Customer, Cost, Convenience, and Communication. 4C theory shifts the focus of research to consumers, and believes that the fundamental goal of marketing is to satisfy consumers, emphasizing the impact of consumer demand and consumer willingness ${ }^{[4]}$.

Because the $4 \mathrm{C}$ theory is too passive to consider the consumer factor, the status quo of market competition can not be well reflected. In this regard, in the early 21 st century, Don E. Schultz ${ }^{[5]}$ proposed the $4 \mathrm{R}$ theory. The theory is based on consumer loyalty and is guided by market competition, including: Relativity, Reaction, Relation, and Retribution. 4R theory believes that enterprises need to establish long-term interaction with consumers in the market competition; it is necessary to establish a rapid response mechanism for market changes; it is responsible for consumers and establish a stable trust relationship; market returns need to be the driving force for development. . While emphasizing marketing relationships, 4R theory also pays attention to changes in market demand and has an important impact on marketing practices.

In the current research, there is little integration of consumer psychology into the above theory. Exploring marketing strategies from the perspective of consumer psychology provides a new direction for the formulation of research marketing strategies.

\section{Consumer psychology and influencing factors}

\subsection{Consumers and their classification}

The International Organization for Standardization (ISO) believes that consumers buy individual members of society who use goods and services for the purpose of personal consumption. In broad and narrow sense, individuals or organizations that purchase products or services in a broad sense can be called consumers, while narrow consumers refer to individuals ${ }^{[6]}$. The most essential feature of consumers is that the purpose of consumer purchase is not for business or sales but for family or individual needs ${ }^{[8]}$. According to the time of consumption, consumers can be divided into past-type consumers, current-type consumers and future-type consumers; according to consumers' attitudes, they can be divided into rational consumers, impulsive consumers, and doubt consumers. And undecided consumers; according to consumer psychology can be divided into advocates, influencers, decision makers, buyers and users.

\subsection{Introduction to consumer psychology}

"Conspiratory psychology refers to a series of psychological activities in the process of purchasing, using and consuming goods." "7] Consumers will produce psychological activities such as feeling, perception, memory, attention, imagination, emotion, and thinking in purchasing behavior ${ }^{[8]}$. These psychological activities will produce four kinds of psychology: truth-seeking, comparison, difference, and herdity ${ }^{[7]}$.

According to Jack Trout's positioning theory ${ }^{[9]}$, according to consumers' consumption motives, consumer psychology can be analyzed from five aspects: consumer values, consumption habits, customs, consumer identity and emotions. (1) Consumer's value psychology: Consumers buy a product because consumers think that this product will bring him greater value than similar products. This value can be a potential value and does not represent his true value. For example, brand name effects, celebrity effects, etc. (2) Consumer's normative psychology: In the actual purchase process of consumers, social norms (principles, reason, friendship, etc.) are an important factor, which can largely influence consumers' purchasing behavior. (3) Consumers' habits: Consumption habits vary from person to person. They have a certain relationship with the environment, experience, and clan of personal life. It is gradually formed in daily life and difficult to change. (4) Consumer's identity psychology: Consumers will always pay attention to their identity during the purchase process. 
According to the psychology of human nature, marketing experts sum up a set of identity principles to make the brand become effective for consumers to express their identity. arms. (5) Consumers' emotional psychology: The consumption process is also the natural inflow of consumer sentiment, and the intangible is also affecting consumers' consumption behavior.

\subsection{Analysis of psychological factors affecting consumers' purchase of houses}

Consumers buy houses mainly to have a good living environment and improve their quality of life. However, different consumers have different preferences and different understandings of the quality of life, which leads to different buying psychology. Factors that usually affect the psychology of buying a house include the house and surrounding environment, the location and transportation, nearby facilities, cost-effectiveness, personal customs and cultural background, and brand appeal. The psychology of consumers buying houses is usually a superposition of the above factors. At the same time, as the age of consumers increases and the standard of living increases, the psychology of consumption will continue to change. Therefore, it is necessary to analyze the psychology and needs of consumers at different stages. To better formulate marketing plans to meet current social conditions.

\section{The application of consumer psychology in real estate marketing strategy}

\subsection{Characteristics of the real estate market}

The real estate market is an area in which real estate transactions agree on the transaction price of a particular real estate and conduct real estate commodity transactions. In addition to the characteristics of general commodities, real estate processing has the characteristics of fixed, regional, imperfectly competitive markets and scarcity. Real estate marketing is the management process of real estate enterprises to understand, satisfy and create customer needs as the center, to achieve corporate goals, and to carry out all business activities ${ }^{[10]}$. The entire marketing process of the real estate market is complex. The design is connected to multiple departments and fields. There are many participants. The whole period of real estate from development to occupancy is long, and the unpredictability is high during the period. For each consumer, every purchase experience is brand new, and these factors pose challenges to the development of marketing strategies.

The formulation of real estate marketing strategy usually includes the following processes (Fig 1) [11]: The first is the analysis of marketing environment, purchasing behavior and internal resources. After the analysis is completed, the target market needs to be adjusted to determine the target market and the market positioning of the product. The market positioning includes product positioning, environmental positioning and image positioning. Then, the most important part is to determine the strategy of real estate marketing, including product strategy, price strategy, sales channel strategy and promotion strategy. Finally, there is a need for proper organization and control of the entire marketing team. 


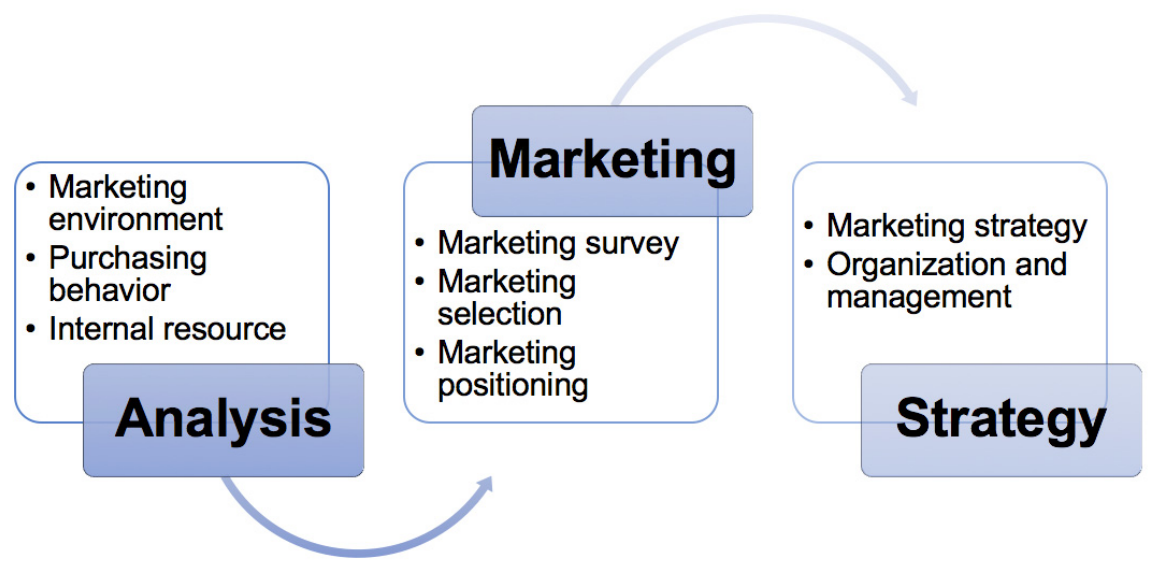

Figure 1: The process of real estate marketing

\subsection{Relationship between consumer psychology and real estate marketing strategy}

The formulation of marketing strategy is, in the final analysis, to solve the relationship between consumers and enterprises. Real estate companies show consumers the value of products through marketing strategies, stimulate consumer behavior and establish stable relationships with consumers, while consumers pass the enterprise Marketing strategies to understand products, determine purchase targets, and more. The relationship between consumers, marketing strategies and products is shown in Fig 2. As can be seen from the figure, consumers and marketing strategies interact with each other. Specifically, the interaction between consumers and products includes consumers' impressions, experiences, associations, etc. on real estate products (Fig 3). Real estate companies design products that combine consumer goals and communicate them to consumers through communication tools. Consumers understand and experience the relevant products and make a comprehensive evaluation of the products. The evaluation of consumers has further influenced the development of real estate products and the formulation of marketing strategies. This has formed an interactive model of consumers and marketing strategies.

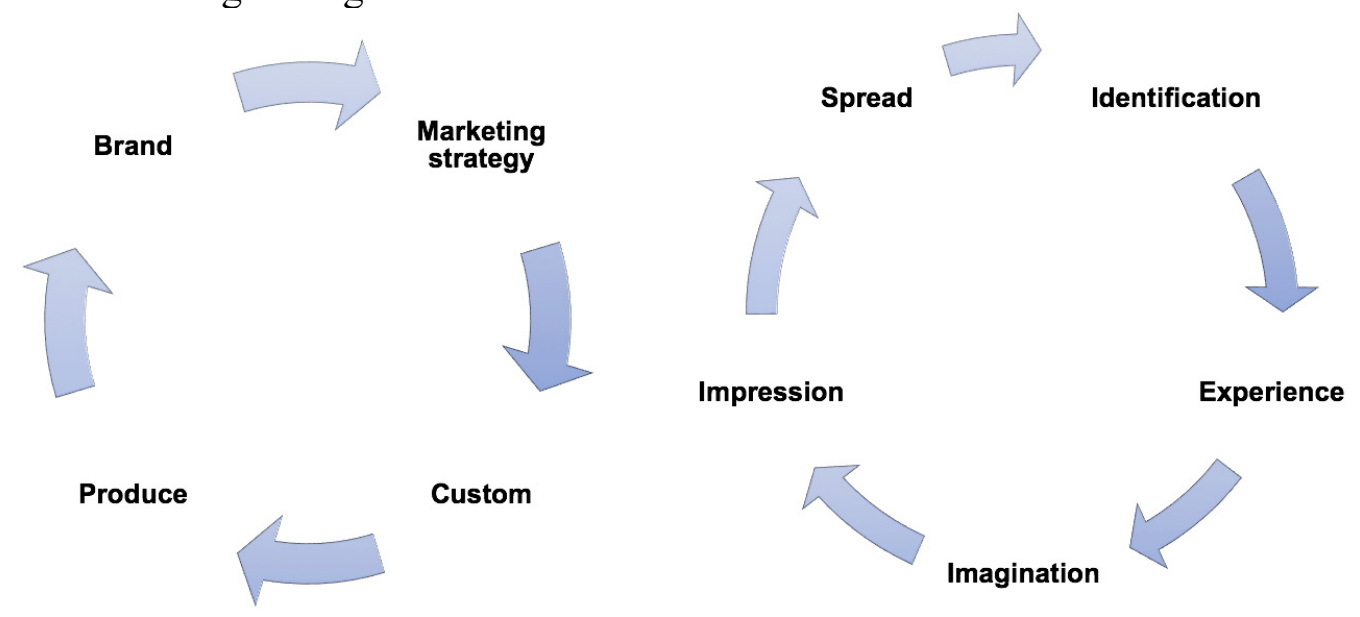

Figure 2: The relationship between consumers, marketing strategies and product

A reasonable real estate marketing strategy plays a large part in the role of a guide, in order to allow consumers to make choices that they consider to be satisfactory among many related products. The marketing scientist Theodore Levitt once gave a famous statement: modern competition does not depend on what different companies produce, but on how much people can care about the products they care about ${ }^{[11]}$. Consumers' consumer psychology and purchasing needs are not only affected by their own factors, but also sensitive to the external environment. Reasonable marketing strategies can 
influence consumers' subconsciousness, build trust between consumers and real estate companies, and then influence consumers. Self-image and impressions of corporate products ultimately reach the role of consumers in recognizing real estate products.

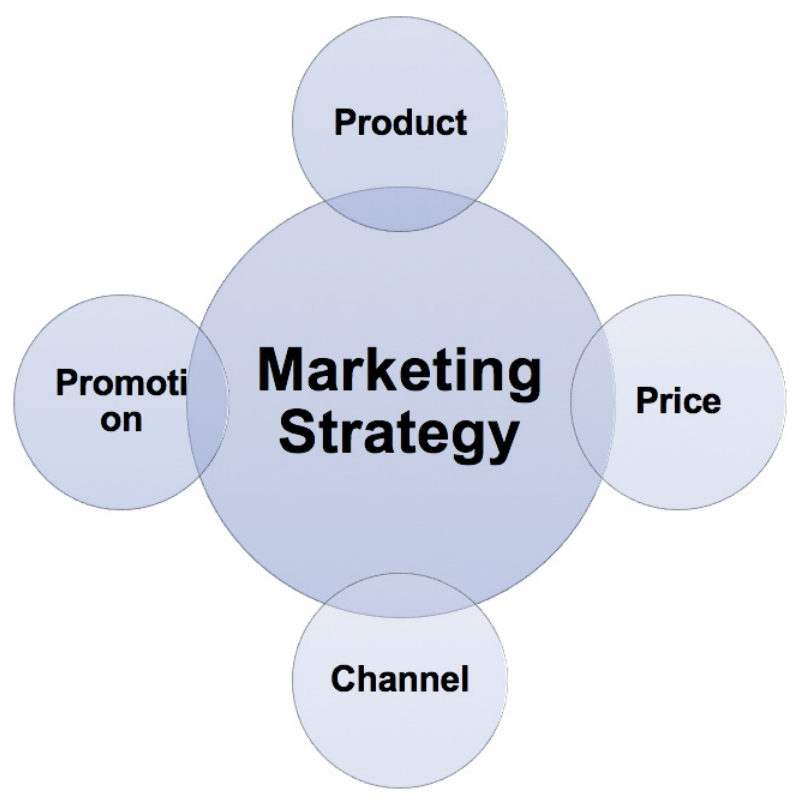

Figure 3: Four of the main factors of marketing strategy

\subsection{Real estate marketing strategy based on consumer psychology}

After analyzing the target market and consumer psychology, it is necessary to formulate appropriate marketing strategies. The formulation of marketing strategies includes product strategy, price strategy, channel strategy, and promotion strategy. This section will discuss the development of the above four elements from the perspective of consumer psychology.

Product Strategy: Product strategy is the core strategy of the company, and any sales are product-centric. Real estate products are any tangible buildings, structures, land and related intangible services that meet the needs and desires of consumers or users ${ }^{[12]}$. At a time when market competition is becoming increasingly hot, it is difficult to establish a single product. This requires the development of a suitable portfolio strategy, including expanding product portfolio strategies, reducing product mix strategies, and product extension portfolio strategies. The combination strategy of real estate products should be constantly changing with market demand. Enterprises must adjust their product strategies at any time to meet the needs of different periods. In the formulation of product strategy, it is necessary to take into account the psychological factors such as consumer value, norms, customs, identities and emotions, and comprehensively consider and formulate product strategies that are consistent with consumers.

Price strategy: Price strategy is the most difficult part of real estate strategy. The price level directly affects the purchasing psychology of consumers. When formulating product prices, it is necessary to consider both corporate profits and consumers' affordability. Changes in the market are adjusted in a timely manner. For consumers, they need to think that the products they buy are worthwhile. They must satisfy this value when pricing. At the same time, the price can not be modified at will, so that consumers do not feel that the products they purchase are not the lowest price. At the same time, for different floors and real estate needs a certain price difference, let consumers take the consideration of the attitude to visit the product.

Channel strategy: Real estate sales channel refers to the process of real estate transfer from producer to consumer. All institutions and individuals that have the right or assistance to transfer ownership of goods ${ }^{[12]}$. Although the channel strategy is directly related to the consumer psychology five, the formulation of the channel strategy will also indirectly affect the consumer psychology. 
When the real estate enterprise formulates the channel strategy, it follows the market law and switches in the mode of direct sales and channel sales.

Promotion strategy: The promotion strategy can not only stimulate consumers to generate purchasing psychology, but also increase consumers' sense of identity with the company and help establish the brand awareness of the company. The promotion strategy should pay more attention to the local history, cultural characteristics and current hot topics, find the consumer's value eagerness, and give this value to the product and pass it to the consumers through appropriate promotion means.

\section{Conclusion}

The marketing strategy based on consumer psychology not only pays attention to the marketing strategy itself, but also pays attention to the psychological activities of the target consumers, and strives to build harmony between the two, and transmits the value of the product to the target consumers through the way of consumer approval. At the same time, the consumer's psychology also acts in tandem with the product strategy makers to develop better marketing strategies, thereby achieving a win-win goal.

\section{Reference}

[1] Feng Wei. Research on customer psychology and marketing strategy in real estate marketing [D]. Chongqing University, 2011.

[2] Guo Guoqing, Liu Fengjun, Wang Xiaodong. Marketing Theory [M]. Renmin University of China Press, 1999.

[3] Engel E, Fischer R, Galetovic A. Highway Franchising and Real Estate Values[J]. Journal of Urban Economics, 2002, 57(3):432-448.

[4] Edelstein R H, Lum S K. House prices, wealth effects, and the Singapore macroeconomy [J]. Journal of Housing Economics, 2004, 13(4):342-367.

[5] Flint D J, Woodruff R B, Gardial S F. Customer value change in industrial marketing relationships: A call for new strategies and research[J]. Industrial Marketing Management, 1997, 26(2):163-175.

[6] Xie Cichang. General Theory of Consumer Protection Law [M]. China Legal Publishing House, 1994.

[7] Li Xiaoxia, Liu Jian. Consumer Psychology (Second Edition) [M]. Tsinghua University Press, 2010.

[8] Yan Lihui. Consumer Psychology [M]. Southwestern University of Finance and Economics Press, 2004.

[9] Jack Trout. "Positioning"is game people play in today's market place [J]. Industrial Marketing, June 1969，51-55

[10] Zhou Zhongyuan. Real Estate Marketing [M]. Shanghai Jiaotong University Press, 2007.

[11] Kotler. Marketing Management: Analysis, Planning, Execution and Control, Ninth Edition [M]. Shanghai People's Publishing House, 1999.

[12] Yu Ying, Zhou Yu. Real Estate Marketing [M]. Dongbei University of Finance and Economics Press, 2005. 